BEST EVIDENCE TOPIC REPORTS

\title{
Towards evidence based emergency medicine: best BETs from the Manchester Royal Infirmary
}

\author{
Edited by Simon D Carley
}

Emerg Med J 2006;23:568-572. doi: 10.1136/emj.2006.038489

Best evidence topic reports (BETs) summarise the evidence pertaining to particular clinical questions. They are not systematic reviews but rather contain the best (highest level) evidence that can be practically obtained by busy practicing clinicians. The search strategies used to find the best evidence are reported in detail in order to allow clinicians to update searches whenever necessary. Each BET is based on a clinical scenario and ends with a clinical bottom line which indicates, in the light of the evidence found, what the reporting clinician would do if faced with the same scenario again. The BETs published below were first reported at the Critical Appraisal Journal Club at the Manchester Royal Infirmary ${ }^{1}$ or placed on the BestBETs website. Each BET has been constructed in the four stages that have been described elsewhere. ${ }^{2}$ The BETs shown here together with those published previously and those currently under construction can be seen at http://www.bestbets.org. ${ }^{3}$ Four BETs are included in this issue of the journal.

- Cocaine induced myocardial ischaemia: nitrates versus benzodiazepines

- The use of loop diuretics in acute renal failure in critically ill patients to reduce mortality, maintain renal function, or avoid the requirements for renal support

- Kocher's or Milch's technique for reduction of anterior shoulder dislocations

- Hyperbaric oxygen therapy in acute fracture management

1 Carley SD, Mackway-Jones K, Jones A, et al. Moving towards evidence based emergency medicine: use of a structured critical appraisal journal club. J Accid Emerg Med 1998;15:220-2.

2 Mackway-Jones K, Carley SD, Morton RJ, et al. The best evidence topic report: a modified CAT for summarising the available evidence in emergency medicine. J Accid Emerg Med 1998;15:222-6.

3 Mackway-Jones K, Carley SD. bestbets.org: odds on favourite for evidence in emergency medicine reaches the worldwide web. J Accid Emerg Med 2000;17:235-6.

\section{Cocaine induced myocardial ischaemia: nitrates versus benzodiazepines}

\author{
Report by Priya Bhangoo, SpR in Emergency \\ Medicine \\ Checked by Andrew Parfitt and Tammy Wu, \\ Consultants \\ St Thomas' Hospital, London, UK \\ doi: 10.1136/emi.2006.038497
}

\section{Abstract}

A short cut review was carried out to establish whether nitrates are better than benzodiazepines in the treatment of cocaine induced chest pain. Seven citations were reviewed of which two answered the three part question. The clinical bottom line is that in patients with cocaine induced chest pain it appears that nitrates or benzodiazepines are effective in combination or alone in resolving chest pain and improving cardiac performance. We recommend that the agent of choice may be influenced by the presence or absence of concurrent CNS symptoms.

\section{Three part question}

In [a cocaine user presenting to an emergency department with chest pain] are [nitrates superior to benzodiazepines] at [resolving chest pain]?

\section{Clinical scenario}

A 21 year old man attends the emergency department complaining of apparent cardiac chest pain. He has no risk factors for ischaemic heart disease but admits to recent cocaine abuse. His ECG appears ischaemic. You wonder how

Table 1

\begin{tabular}{|c|c|c|c|c|c|}
\hline $\begin{array}{l}\text { Author, date, } \\
\text { country }\end{array}$ & Patient group & Study type & Outcomes & Key results & Study weaknesses \\
\hline $\begin{array}{l}\text { Honderick } \\
\text { et al, } \\
2003 \text {, } \\
\text { USA }\end{array}$ & $\begin{array}{l}27 \text { patients attending ED, } \\
\text { chest pain }<72 \text { h duration. } \\
15 \text { treated with NTG } \\
\text { alone, } 12 \text { treated with NTG } \\
\text { and lorazepam. NTG } \\
\text { group then crossed over }\end{array}$ & $\begin{array}{l}\text { Randomised } \\
\text { prospective } \\
\text { single blind } \\
\text { control }\end{array}$ & $\begin{array}{l}\text { Pain score, chest } \\
\text { pain severity }\end{array}$ & $\begin{array}{l}\text { Mean pain score at } 5 \text { min } \\
1.24 \text { lower in NTG and } \\
\text { lorazepam group }(p<0.02)\end{array}$ & $\begin{array}{l}\text { Convenience sample } \\
\text { Sample size small } \\
\text { No placebo arm for iv } \\
\text { lorazepam } \\
\text { Unusual therapeutic regimen } \\
\text { No follow up }\end{array}$ \\
\hline $\begin{array}{l}\text { Baumann } \\
\text { et al, } \\
2000 \text {, } \\
\text { USA }\end{array}$ & $\begin{array}{l}44 \text { patients attending ED, } \\
\text { all took cocaine within } \\
24 \mathrm{~h} \text { (median } 5 \mathrm{~h} \\
37 \mathrm{~min} \text { ) with history } \\
\text { suggestive of ischaemic } \\
\text { chest pain, age } 18-60 \\
\text { years }\end{array}$ & $\begin{array}{l}\text { Randomised } \\
\text { control, double } \\
\text { blind placebo } 7 \\
\text { control }\end{array}$ & $\begin{array}{l}\text { Pain score, chest } \\
\text { pain severity } \\
\text { Haemodynamic } \\
\text { performance and } \\
\text { cardiac } \\
\text { performance }\end{array}$ & $\begin{array}{l}\text { No difference between either } \\
\text { agent alone or in combination } \\
\text { in terms of score reduction } \\
\text { When baseline differences adjusted, } \\
\text { statistical comparisons showed no } \\
\text { demonstrable difference }\end{array}$ & $\begin{array}{l}\text { Possibility of concomitant } \\
\text { coronary artery disease, } \\
\text { anxieties regarding perception } \\
\text { symptomatology by cocaine } \\
\text { users, possibility of non- } \\
\text { ischaemic chest pain }\end{array}$ \\
\hline
\end{tabular}

NTG, nitroglycerin. 
nitrates or diazepam, in combination or alone, compare at resolving chest pain and as regards clinical outcome.

\section{Search strategy}

Medline 1966 to February 2006 using the OVID interface: [ $\{\exp$ cocaine OR cocaine-related disorders.mp. $\}$ AND \{exp chest pain OR ischaemia OR angina OR acute coronary syndrome OR infarction.mp. $\}$ AND \{exp diazepam OR exp benzodiazepines OR nitrates.mp. $\}$.

\section{Search outcome}

Seven papers found of which two were relevant (table 1).

\section{Comment(s)}

The demographics of both study populations are comparable to that of cocaine users attending the emergency department. The presenting electrocardiograms were largely normal in these patients. Treatment was based largely on history and symptoms. Nitrates were used sublingually. Diazepam was administered intravenously. Very small numbers and the lack of a placebo for lorazepam in the second paper may be responsible for the reduction in pain scores seen when patients received both agents.

\section{- CLINICAL BOTTOM LINE}

In patients with cocaine induced chest pain it appears that nitrates or benzodiazepines are effective in combination or alone in resolving chest pain and improving cardiac performance. We recommend that the agent of choice may be influenced by the presence or absence of concurrent CNS symptoms.

Baumann BM, Perrone J, Hornig SE, et al. Randomized, double-blind, placebocontrolled trial of diazepam, nitroglycerin, or both for treatment of patients with potential cocaine-associated acute coronary syndromes. Acad Emerg Med 2000;7(8):878-85

Honderick T, Williams D, Seaberg D, et al. A prospective, randomized, controlled trial of benzodiazepines and nitroglycerine or nitroglycerine alone in the treatment of cocaine-associated acute coronary syndromes. Am J Emerg Med 2003;21(1):39-42.

\section{The use of loop diuretics in acute renal failure in critically ill patients to reduce mortality, maintain renal function, or avoid the requirements for renal support}

\section{Report by Anthony Davis, SpR in Anaesthesia Checked by Ingrid Gooch, SpR in Anaesthesia North West School of Anaesthesia, Manchester, UK doi: 10.1136/emi.2006.038513}

\section{Abstract}

A short cut review was carried out to establish whether loop diuretics are useful for critically ill patients with renal failure. A total of 1017 citations were reviewed of which two answered the three part question. The clinical bottom line is that in critically ill patients with acute renal failure, there is no evidence to suggest that the use of loop diuretics reduces mortality, reduces length of ITU/hospital stay, or increases the recovery of renal function.

\section{Three part question}

In [critically ill patients with acute renal failure] does [the use of loop diuretics] [reduce mortality, improve renal function, reduce length of ITU/hospital stay, or reduce requirements for renal replacement therapy]?

\section{Clinical scenario}

A 65 year old male presents to the emergency department with severe pneumonia. He is intubated and placed on a ventilator because of worsening hypoxia. He has no history of previous renal disease but becomes increasingly oliguric over the next $2 \mathrm{~h}$ despite adequate fluid resuscitation and vasopressor support. You wonder whether the administration of a loop diuretic in order to improve/ maintain his urine output would improve his prognosis and reduce the need for continuous veno-venous haemofiltration (CVVH).

\section{Search strategy}

Cochrane Database, Edition 2, 2006: Loop diuretics. OVID Medline 1966 to February week 1 2006, and EMBASE 1980 to February 2006: (exp Uraemia OR azotemia.mp OR exp Kidney Failure/ OR exp kidney failure, acute/ OR exp kidney tubular failure, acute/ OR acute tubular necrosis.mp OR acute renal failure.mp OR renal failure.mp OR acute kidney failure.mp OR ARF.mp) AND (exp Diuretics/ OR Diuretics.mp, OR loop diuretic\$.mp OR exp furosemide/ OR frusemide.mp OR exp bumetanide/ OR bumetanide.mp OR burinex.mp OR lasix.mp OR torasemide.mp OR Torem.mp) and ((critically ill or critical illness).mp OR exp Critical Illness/ OR critical care.mp OR exp Critical Care/ OR intensive care.mp OR intensive care units.mp OR exp intensive care/) limited to English and humans.

\section{Search outcome}

A total of 97 papers were found on Medline and 721 papers on EMBASE of which only two directly answered the three part question (table 2). There were 209 citations in Cochrane. No new papers were found.

\section{Comment(s)}

About one fifth of the cardiac output is directed to the kidneys. This exceeds the oxygen supply to other vital organs, such as the brain, heart, or liver. A very low fraction of oxygen delivered is extracted by the kidney, suggesting ample oxygen reserve. Paradoxically, the kidney is the organ which is most sensitive to hypoperfusion and hypoxia, with acute renal failure being one of the most frequent complications of hypotension. This is because of the physiological gradient of intrarenal oxygenation, which means that under normal physiological conditions the renal medulla functions at very low oxygen tensions. Many therapeutic interventions in the prevention or management of patients with acute renal failure have been investigated in clinical studies. Interventions to enhance renal blood flow and decrease tubular reabsorption seem to be a logical approach for the prevention of outer medullary hypoxic injury. Loop diuretics block the active sodium-potassium-chloride co-transport in the apical membrane of the thick ascending limb renal tubular cells. The loop diuretic frusemide has been shown to reduce medullary demand by inhibiting solute reabsorption and to attenuate the severity of acute renal injury in animal models. It is postulated that it may protect the human kidney from ischaemic injury. There are some small studies of low statistical power, but they are confounded by co-interventions such as low dose dopamine or mannitol. The best evidence to answer this current clinical question comes from the two observational cohorts identified in this review. The two studies collected over 2000 patients. They both document overall detriment with the use of diuretics with odds ratios of $>1.0$, as opposed to benefit, although the BEST investigators did not demonstrate statistical significance in their findings. 